\title{
Participation in Botswana: A Case Study of Botswana National Association of Social Workers (BoNASW)
}

\author{
Kgomotso Jongman ${ }^{1}$ \\ ${ }^{1}$ Department of Social Work, University of Botswana, Gaborone, Botswana \\ Correspondence: Dr. Kgomotso Jongman, Lecturer, Department of Social Work, University of Botswana, \\ Private Bag 00750, Gaborone, Botswana. E-mail: JongmanK@ub.ac.bw
}

Received: April 14, 2020

Accepted: May 1, 2020

Online Published: May 26, 2020

doi:10.20849/ajsss.v5i2.746

URL: https://doi.org/10.20849/ajsss.v5i2.746

\begin{abstract}
Professional participation in Botswana has been lagging behind since the conception of the social workers association in the past 20 years. Participation in the professional body of social workers have been has a headache for the leaders of the national association. The numbers of social workers attending social work events such as the social workers day, leadership forum and the annual general meetings have been going down over the past 10 years since the official launching of the national association. This unfortunately is not only peculiar to social work, but it seems it worse among social workers. This has left those who are in leadership of the profession with many questions. The most important Questions that have been asked have been; what's wrong with the social work profession where the participation in the professional bodies has been below par? Is it the problem of social workers only in Botswana or there is apathy all over? This paper has combined the shared information, experience from the author as the president of the association for 6 years, being the advisor for 4 year and now just an ordinary member but holds a position of International Federation of Social workers Human Rights commissioner in Africa. The paper also tries to look at the literature on participation in general.
\end{abstract}

Keywords: participation, social work, BoNASW

\section{Introduction}

Mazibuko and Gray (2004) have indicated that, the origins of the social work profession can be traced to the industrialized Europe and North America, as attempts were made to respond to the societal needs of the time. It was later imported to Africa in the late $19^{\text {th }}$ century. In Botswana it can be traced to 1946 , when the first social welfare officer was placed at the ministry of education (Ferguson-Brown, 1996). With that being said, Professional training of social work came a bit late in 1974 which still rudimentary and it offered a certificate in social welfare and community development. The training moved to University of Botswana in 1985 to offer, certificate, diploma and degree in social work (Jongman, 2015). Since then, the University of Botswana has produced a significant number of professionals and Para-professional graduates into the field of Social Work, at the Doctoral, Masters, Bachelors, diploma and certificate levels. These graduates are then employed in different organizations that deal with human services in the country. For the large extent, the Department of Social and Community Development (S\&CD) under the Ministry of Local government and rural development has been the largest employer of social workers (Lucas, 2018). Those under S\&CD work in different parts of the country ranging from urban, peri-urban, rural areas and remote areas mostly with minimal resources. The above-mentioned department is not the only one employing social worker. Since the 1990s according to Lucas (1993) the profession of social work has grown and reached into other departments such has, Botswana Defence Force, Botswana Police Service, Health sector, Non-governmental organisation and in the millennium, they moved to the department of youth.

In trying to have social workers speaking with one voice despite different departments and regions of operation, the association of social workers was formed in the earlier 1990's (Jongman, 2015). The objective of the association according to Jongman (2015) was to bring the profession to one voice and advocate for the profession, fight injustice especially for the vulnerable of the community. The association has gone through different stages of forming, storming, disintegrating revival and just surviving. All these challenges that have been highlighted above have been due to lack of active participation among social workers in Botswana. The author of this article who has been the president of the association for 6 years and now a lecturer at the 
University of Botswana has observed that, there is a paradox in terms of participation in the association by social workers. The paradox is that, while at, undergraduate students are actively involved in the University of Botswana social work society (social work students) and in the national association but when they get employed, they cease to participate in the activities of the association. This has left many wondering what the problem might be or what are the challenges to be engaged with the association when someone is in the work environment. This will be a point for research some other time.

The association is doing all it can to encourage social workers to participate in its activities and programmes. The association has come up with structure to enable people to participate at the micro and mezzo levels such as having regional coordinators in all districts in Botswana ( 8 regions) to spread the messages about the association to social workers countrywide. Invitation to members are sent well on time, for example invitations on the Annual General Meeting of the Association are sent 3 months before the activity could actually take place to give people time to prepare themselves yet they are still reluctant to come and only few social workers take part in such an activity. Taking the 2013/14/15/16/17 and 2018 AGM report (Note 1), it is shown that there were only 150 registered members out of over 5000 social workers in the country but only 80 members attended the Annual General Meeting.

As a non-profit organization, BONASW membership programs provide opportunities for establishing social networks. Different people are invited to most activities carried out to give social workers an opportunity to network with them. Those in rural areas have limited chances of networking and professional development while at work therefore the activities of the association provide platform for them, yet they still do not attend. This then lead one to ask him/herself a question about what agencies are doing to encourage participation of social workers on the activities of their association. Invitations are sent while there is time, do agencies allow their employees to attend or is it the social workers on their own freewill who decide not to attend and why is that the case?

This paper therefore seeks to give an oversight of the effect of participation on a specific group of people. The paper starts by addressing issues of methodology and theoretical framework, giving a brief definition of participation which is then followed by a brief history of participation in Botswana. The paper continues to elaborate on the major contributing factors which may lead to non-active participation and last but not least the paper gives a way forward that the Botswana National Association of Social Workers can use to improve and enhance participation in the activities of the association.

\section{Methodology}

For any scientific activity there should be a scientific method to indicate how the data was obtained and how it was analysed and how the author arrived at certain conclusions. In this paper, there is going to be critical review of literature, the use of the needs assessment study by the national association of social workers in 2013, anecdotal information, reports from the Annual General Meetings and finally the experience of the author as the president and advisor of the association.

\subsection{Theoretical Framework}

Participation in a professional body is mostly voluntary and people are always asking what is there for me. Instead of committing time to the association they will rather commit the time somewhere were their time will be tangible results. In this case, if the association would like to improve the participation, social exchange theory will be the most appropriate framework going forward. In a sternly scientific sense Lub (2019) refer to theory as a coherent description of a process of inference which provides an explanation for observed phenomena or makes predictions about those phenomena. Furthermore, Michie, West, Campbell, Brown \& Gainforth (2014) indicate that, in the context of behavioural and social change, theories attempt to explain why, when and how certain behaviour may or may not occur and indicate the main sources of influence to change the targeted behaviour. Much of social life involves interactions between individuals or corporate actors in dyads, groups, organizations or networks that can be viewed as social exchanges (Cook, Cheshire, Rice \& Nakagawa 2013). Social Exchange Theory is an important social psychology concept that concerns social changes as a process of interactive exchanges between different people. In addition, this theory is often used within the business world to explain and analyse commercial transactions. In this theory, human interactions and exchanges are viewed as a kind of results-driven social behaviour. At the centre of the social exchange theory is cost and rewards. This means that cost and reward comparisons drive human decisions and behaviour. Costs are the negative consequences of a decision, such as time, money and energy. Rewards are the positive results of social exchanges. Therefore, the generally accepted idea is that people will subtract the costs from the rewards in order to calculate the value. Social workers are looking at the cost and rewards of participating in the association. The results of cost analysis benefit will either make them participate or not participate. 


\section{Participation}

It is important to look at participation at in a broad sense to get the understanding what participation is all about. Participation is part and parcel of social work and social work as profession promotes participation by those who are receiving service from social workers. For social cohesion as captured in the global definition of social work (IFSW, 2014) to take place there should be some form of participation in the community. In its simplest form, participation might mean, people being involved in decisions that affect their lives. Through participation people can identify opportunities and strategies for action and build solidarity to effect change. In terms of the Literature, on participation, it categorises participation into two categories which is: empirical studies describing patterns of participation behaviour, and theoretical studies seeking to explain that behaviour. Furthermore, Zaman (1984) Observes that there are two distinct ways through which participation can be achieved; self-determination participation and mobilized participation. The other elucidates that, Self-determination participation holds that people have an inherent desire to partake in local social development activities while mobilized participation presupposes that there is need for external agents to stimulate and mobilize local people to participate. On one hand at BONASW there are a few social workers who willingly participate in the activities of the association hence making them self-determinant participants; on the other hand, there are those Social Workers within the association who needs encouragement and motivation to actively participate in the association and such people can be identified as mobilized participants.

Most of the time participation mechanisms use the least restrictive method of selecting participants. One of the methods used is self-selected subset of general population (Fung, 2006). This implies that participation is open to those who wish to take part. One will find that most of the people who choose to participate are quite unrepresentative of any large public since they tend to become passive. This is evident with the participation of social work at the annual general meetings and in association matters in general. They only represent less than $10 \%$ of the total social work number in the country. The principal reason for improving citizen participation in any area of contemporary governance is that the accredited set of decision makers-typically elected representatives tend to be somehow deficient in ways of encouraging members to attend the organization activities (Fung, 2006). This is supported by Fung, (2006) saying that "they may lack knowledge, competence, public purpose, resources or respect to command compliance and cooperation". One would find that in BONASW there is an issue of limited resources since the association has no sustainable form of income and struggles to find sponsorship or event to raise funds to run itself. This issue of limited resources has a huge impact in the running of the association as they face challenges when it comes to mobilization to invite people to the activities of the association, they cannot reach social workers who work in remote areas like New Xade in the Gantsi district well on time. Fung (2006) further states that, individuals who are wealthier tend to participate more than those who lack these advantages. This may be due to the fact that people who are wealthier have resources. That is to say they can be able to access any place that the activities are held as compared to those who have lack of resources. For instance, in BONASW, social workers who works in remote areas at times fail to attend the activities of the association due to the fact that government did not provide any transportation to the association activities.

Being part of any association encourages bonds and tight relationships amongst members of the association. This increases participation in a way that the members of the association will be able to communicate and encourage others to participate in the activities of the association, in the case of BONASW the social workers will be motivated to call their colleagues using their personal mobile phones and update them. Moreover, Teorell (2003) posits that being connected to a voluntary association is in it social capital since it ties an individual to a network of relationships amongst the association members. This supports socialization in a way which improves participation. Furthermore, Teorell (2003) tries to explain why members cannot participate, members do not participate, and nobody asked them to participate.

\subsection{History of Participation in Botswana}

In Traditional Botswana, the economy was basic, and people lived and helped each other to alleviate any societal or human suffering (Jongman, 2015). The introduction of money markets in the colonial era saw the erosion of volunteerism and community participation. Jongman (2015) elucidates that, the hut tax and World War II saw many men going to South Africa and that disintegrated the family structure that finally led to individualism (Ferguson-Brown, 1996). After 1966 when Botswana was gained independence; the government was under a lot of pressure due to the severe drought. Initially community development encouraged people to work together for the development of the community and this benefited a lot of people in those communities (Hendiquest, 1992). The government engaged in food for work scheme to encourage people to develop their communities while they benefit. Ngwenya (1991) believed that, this initiative was the source for eroding the self-help and community participation in Botswana. In this case, many members of the community although invited to participate in 
meetings about their developmental needs remained passive in the process because of their primary motivation for immediate gain. It was this offer of food that had serious repercussion for community development because the food aid scheme was linked to development programs offered food as payment for development work (Hedenquist, 1992).

The motivation for community members to participate in community development projects was not for the project and its benefits to the community but the food provided for labour at a vital time of drought. (Ferguson-Brown, 1996). (Rankopo, 1996) agrees with Ferguson-Brown (1996) on a study he did at Bokaa which showed that men wanted to be paid for their labour even if the projects were self-help projects.

The food for work scheme left an imprint in the minds of the Botswana society as people were now reluctant to volunteer their services without anything in return. The legacy of the food for work scheme can be seen today especially in the association as the results of the needs assessment that the association conducted in 2012, shows that some people are disinterested to join the association simply because they think it does not benefit them in anyway (Note 2). This shows that these people with such mentality only want to join the association only if they will get tangible returns. The food for work scheme also associated social workers with handouts as they were delegated to assist in the process. Its effects manifests today as many citizens are struggling with defining the roles of social workers in the community hence citizens consider social workers as responsible for distributing food rations with the country.

The food for work scheme ended on the 30th of September 1967 and all incomplete projects were the responsibility of the community development department (Hendiquest, 1991). The department gave material help in the form of money and material to communities wishing to construct buildings for the benefit of the whole community. In addition, the department also encouraged the creation of village development committees wherever the community development assistants were available (Hedenquist, 1991).

Rankopo (1996) Stated that the first village to form a village development committee (VDC) was Bokaa in 1967, with lots of projects that were put on board. VDC like in other voluntary associations, participation has long been important in supplying societal goods and services and bringing satisfaction and meaning to individuals. Therefore, the villagers at Bokaa realized that there was a shortage of accommodation to teachers. Even if the government did not assist them, they did not lean back, they took the projects themselves and implemented them because they believed they needed teachers so that their children could receive the maximum education that they could ever find. There was overcrowding in the classrooms with a single teacher responsible for lots of children so they found it appropriate to have more teachers so that at least the class would be divided into half for effective learning (Rankopo, 1996). This clearly shows the motives behind the people of Bokaa participating in voluntary work.

Social Workers can learn from what the Bokaa villagers. It does not mean that if the association lacks resources that means there are no activities that could be carried out. Social workers should stand up and fight for their association to be fully recognized and thus attracting more membership.

It is worthy to note the struggles of the social work from its origin which in most case could be associated with demoralizations and reluctance of social worker's participation in the association. Such struggles worked mostly against social workers themselves and really held back proceedings and development of the social work profession which can be clearly reflected today. In the 1990s social work was faced with a huge challenge of disconnect, the principals in social work were under the Ministry of Labour and Home Affairs while the operations and service provision of social welfare was under the Ministry of Local Government (Jongman, 2010). This was a huge challenge to the social workers because in most activities they wanted to do, they were demoralized by bureaucratic process to follow which led to social workers being caught in between the two ministries at times. This also impacted on the management of the association.

\subsection{Urbanisation and Participation}

Traditionally, people believed that living in urban areas were not conducive for interactions among people. The lack of social integration and the weakness of social ties in general also made it more difficult to mobilize city dwellers for various forms of engagement. It was assumed that urbanization would have a negative impact on most forms of social participation. Urban life was equated with anonymity, a lack of strong social ties and a reduced possibility for the individual to exert any influence in social life (Fischer, 1975). This was due to the fact that urban areas were associated with lack of voluntary associations, religious institutions and family ties which allowed people to bond easily. Remmer (2010) has confirmed these findings in a comparative research project, arguing that residents of large-scale communities have less reason to assume that their individual contribution could make a difference in the way their society is being run. 
On a contradicting study that was done on Rural-urban divides in participation in voluntary organization by Botterman, (2011), it was found out that urbanization does not affect participation. Samson (1988) has found that city size does not have an effect on the scope or the extensiveness of friendship networks, while Steblay, (1987) also did not find the rural-urban division to have any effect on helping behaviour. Urbanization does not have a significance impact on either the scope or intensity of participation in voluntary associations. As a result, social workers in Botswana do not have a reason not to participate because they are in rural areas or urban areas. Information is conveyed equally to every social worker in the country and same opportunities are given to each social worker in the country.

\section{- Time and participation}

Riuter, (2011) Says that when people have less leisure time available, it becomes more precious to them, making it more costly to engage in volunteering. This implies that people's voluntarism depend on the time they have that is free, and if they have most of their time busy; it means they get tired and need some time to rest and in this case they end up not having time to participate in voluntary work. In addition, Riuter, (2011) continues by saying that people with part time jobs tend to participate more on voluntary works than those people who have full time jobs. That is to say, people with part time jobs have plenty of leisure time as compared to those who work full time jobs. An example would be; with Botswana civil servants, one would find that the workers go to work at 07:30 am and dismiss at $16: 30 \mathrm{pm}$, at this time they do not get enough time to do voluntary work since they are tired at the time they dismiss, and they also have social responsibility and to take care of such as attending to family matters.

\section{- Gender and participation}

Studies in Botswana though in the past have shown that women for instance have less leisure time yet still get involved in community projects. A study that was done by Rankopo, (1996) on gender and participation clearly indicated that women are devoted to self-help despite the fact that they have equally demanding responsibilities. Women are mothers, wives, household managers, farmers and members of many village community organizations but they are able to strike a balance between all these other roles.

In this regard social workers can be able to participate in the activities of their association. This is because firstly activities do not take place every day; secondly, social workers are informed well in time that there will be an activity or a meeting giving them enough time to cater for the activity in their daily schedules and thirdly, even if there are meetings after work, the meetings are usually short enabling people to go to their households to do their chores leaving social workers with no reason to say they do not have time to take part in the activities of their association.

Time is not the only factor that leads to less participation. Some workers join many associations and they hold positions which lead to prioritizing other associations over the other, and in such cases, people will just register with an association and become passive by not attending activities and events that are organized in the association. Being engaged in numerous organizations implies that people have to distribute their time and have an average less time available to invest in each of these organizations, compared with people that are affiliated with only one organization (Ruiter 2011). Being passive member in the association or organization means that such member will not contribute in the decision making of the association since consultation will be done in his/her absence thus leading people to making decision for a passive member.

\subsection{Importance Participation}

Membership in the relevant professional association is one of the phenomena that distinguish a profession from a conventional job. The above explained, is a key element that defines a professional. Membership in one's professional association is expected of all professionals. Furthermore, it is important to support the advancement of one's profession and becoming a member of the professional association and this is a part of that advancement in professional development. Moreover, Participation is an important aspect in decision making since the association seeks to pursue and achieve its interests and goals, therefore there has to be consultation with the members to come up with new and diverse ideas. It is clear that participation is meant for a team's ability to turn new ideas and individual held knowledge into innovative, creative services and products as stated by De Dreu, (2001). Moreover, it is important to work as a team since the members get to learn from others as they come with different strategies as they strive to achieve their set goals. Looking at the Botswana National Association of Social Workers (BONASW), they hold several events where they invite members to attend for the way forward of the association. This is supported by West and De Dreu (2001) when they asserts that, participation fosters learning through acquisition, sharing and combining of knowledge that each members of the association tend to become more close to each other and enjoy coming to the events of the association. 
Participative decision making and autonomous teamwork is effective because if subordinates have task relevant knowledge and are allowed to implement it, the resulting decision should have a positive effect on the performance De Dreu, (2001). Generally what the authors is emphasizing is that if there is high participation by the members of the association they will have their work divided, that is division of labour and specialization, thus good results will be produced as a result of impressive participation by the association members. In addition to that, they stated that the minority act together to predict innovation in teams, that is higher levels of minority dissent lead to more divergent thoughts and creative ideas but only under high levels of participation. Likewise, the Botswana National Association of Social Workers has few members registered with association, so if the registered members could actively participate in the events and/or activities they could bring about positive results.

There is considerable evidence that suggests that Batswana have always taken an active interest in the deliberation and implementation of communal self-development projects in their villages long before the establishment of modern government (Inger, 1985, Ngwenya, 1991). This was achieved through the process of Therisanyo at the Kgotla. Therisano allows people to openly debate communal issues before reaching a decision by consensus on course of action.

\subsection{Challenges of Non-participation by Social Workers}

It is highly imperative that social work students should be taught the importance of professional association. The Professional social work association by nature, it supposed to have many members from across different environments hence connect social workers across the country and the world. Furthermore, the association offers many valuable networking opportunities for students and graduates. Professional associations can help students find employment, and they provide a way to share ideas. The association host events for early-career professional, training seminars and other events that allow members to network and learn new techniques and skills from each other. Joining a professional association is a great way for social workers and students to develop professionally.

By nature, social work endeavour to promote social justice and is based on human rights so has to promote distributive justice. This justice can only be achieved through advocacy which is one of the roles of social workers. As indicated in the IFSW and IASSW (2014), global definition, social work promotes social change and social workers cannot promote social change if they will not be able to change their own environment. In Botswana, social workers are among the most unrecognised and unrewarded profession, who are only remembered in times of adversity like the corona virus pandemic. They are thrown into the deep end without any protective clothing or equipment. They have to go on and do their work. This is due to the fact that, they don't have a united voice, they are scattered all over the ministries and departments without guidance. Government of Botswana also does not know where to find social work leadership. Moreover, there is no regulatory body that guides social workers in Botswana, this has led government to use social workers in anyway they want, and also this has led social workers to perform in anyway they want because there is no regulatory body to regulate by licensing practice. As earlier indicated, social workers are underpaid but there is no voice to advocate for better, paying structure, personal development, working conditions and proper supervisory structures. All the above-mentioned reasons are the repercussions of not having a fully functioning professional association. If social workers are not fully participating in their association, they cannot be distinguished from the rest of the social service professionals because they don't have standards that guide their practice.

\section{Findings and Discussions}

After critical analysis of literature and zeroing into the needs assessment that was commissioned by the association in 2012, there are few issues that have been teased out as the impending elements to participation in the association.

- Activities are not professionally stimulating- from the need's assessment, social workers have indicated that, activities of the association are not professionally stimulating, there are mostly administrative and boring. Social workers are looking for activities that will challenge them. This goes back to the social exchange theory that, if the cost is over the benefits people will choose what will benefit them more. With this, the association should engage the University of Botswana and other international schools of social work to come and discuss issues that affect the profession of social work.

- Lack of knowledge, competence, purpose and resources- it is clear social workers do not understand the role of the professional association. Furthermore, there is a confusion between the role of a professional association and labour union. People because have joined labour unions they believe it is the ultimate (Bonasw, 2012). The training from the University of Botswana is lacking in terms of 
touching all aspects of social work. The issue of professional body is lagging behind and needs to be taken on board.

- Frustration and demoralised - social workers have indicated that they are frustrated to be in the profession. The needs assessment has indicated that majority of the participants in the assessment had indicated that they did not want to do social work, but university of Botswana just admitted them for social work. With this, its easy to get frustrated and when they are frustrated at work its not easy to be part of the association because it will just overload them with more frustration.

- Culture of inertia and apathy- the United Nations Happy People index since 2013 has been indicating that Batswana are among the unhappy people of the world. This has shown with their inertia and apathy in anything. This has been felt more by the association. The lack of interest and urgency in issues of the association are a cause for concern.

\section{Way Forward to Improve Participation}

\section{He who conquers himself is the one to save others.... Mahatma Ghandi}

The above quotation from Mahatma Ghandi shows that, for social workers to be able to advocate, they need to start with themselves and make a difference in the profession. There will be no one coming from outside the profession to help them to fully and actively participate in the association. They need to start making the association more attractive and be part of the process. Social workers need to join BONASW and motivate themselves to be able to enjoy the activities offered by the association. Most activities require monetary resources to be carried out as result each non-profit organization need to come up with ways of raising money that will enable them carry out their activities as well as attracting members to join the organization.

Rankopo (1996) in his study on community participation in village self-help projects in Botswana specifically looking at Bokaa village, Rankopo (1996) found out those villagers at Bokaa participated more looking at the benefits that they will receive. Villagers actively participated in building a house for sergeant police officer in their village. They were tired of waiting for their cases to be tried by a prosecuting officer from other villages who came whenever he has completed tasks at his own village first. They sometimes waited for a long period before someone could come to their village for the cases. Because the project would improve the social service in their village, they participated more by making bricks and building the house themselves. Therefore, it is also upon BONASW to come up with ways of attracting people to the association because unlike in the past, associations are joined for the benefits they bring along. Social work has grown since the 1990s and have moved into different departments, the association should attract social workers from different organisation, the narrative in the association should not only be on the administrative issues but also professional issues that cuts across the different departments. Michael, Keller, Tran, Sayles, and Custer (2016) believe that, the role of a professional society, organization, or association is to offers its members the prospects of advancing their knowledge and skills and to maintain their certification through organizational activities. In advancing the knowledge in skills of members of the association, Bonasw should start engaging in public debates to engage in topical issues and offer solutions to challenges and social issues that are cladding the country. The marketing of the association should also change with time, flyers (soft copies), Youtube videos, Facebook and twitter should be used as a marketing strategy to reach out to more social workers especially those who are outside the government. The association should host symposiums for students, go to international conferences, publish books and journal articles. They should be present and alive especially with attracting young social workers who cannot stand the long meetings. They should introduce technology in the way they deal with issues and reaching the people.

\section{Conclusion}

Clearly there is need for further documentation on issues pertaining to the Botswana National Association of Social Workers. The association really needs to market itself and attract more members so they can strive forward together for the greater good of its members. The association really needs to put more energy in mobilization and recruiting new members to join the association. However, the association should complement mobilization with seminars and skills training which will keep the registered members motivated to continue participating in the association. Moreover, the association should push for the establishment of the social workers Act which will establish the council of social work so that profession can be regulated. Participation should be emphasized from the social work education where students are exposed to things like conferences (local, regional and international). From, the literature that has been reviewed in this paper, and sharing of experience, it is evident that there is also a need for fully fledged research to find out why are social workers not participating in the professional association. This will give a scientific evidence and come up with ways on how the participation can be improved. 


\section{References}

Botswana National Association of Social Workers. (2012). National Needs Assessment, BoNASW.

Botterman, E. H. (2011). Urbanization, Community Size, and Population Density: Is there a Rural-Urban Divide in Participation in Voluntary Organization or Social Network Formation?. Non-profit and Voluntary Sector Quarterly, 120-144.

Cook, K. S., Cheshire, C., Rice, E. R. W., \& Nakagawa, S. (2013). Social Exchange Theory. In DeLamater, J., \& Ward, A. (Eds.), Handbook of Social Psychology. Handbooks of Sociology and Social Research, Springer, Dordrecht.

De Dreu, M. A. (2001). The Importance of Participating in Decision Making. Minority Dissent and Team Innovation, 1991-1201.

Ferguson-Brown, H. (1995). Social Work and Social Development. Gaborone: Ministry of Local Government, Land and Housing, Government Printers, Gaborone.

Fischer, C. (1975). The Effect of Urban Life on Traditional Values. Social Forces, 53(3), 420-432. https://doi.org/10.2307/2576584

Fung, A. (2006). Varieties of Participation in Complex Governance. Collaborative Public Management, 66(Special Edition), 66-75

Hedenquist, J. A. (1991). Introduction to Social and Community Work in Botswana. Gaborone: Ministry of Local Government, Land and Housing.

International Federation of Social Work (IFSW) and International Association of Schools of Social Work (IASSW). (2014). Global definition of social work. Retrieved from https://www.ifsw.org/global-definition-of-social-work/

Jongman, K. (2010). Challenges Faced in Setting up the Botswana Social Worker's Association: Implications for Social Work Practice. In Social Welfare Strengthening Conference, (pp. 7-10). Cape town: IFSW.

Jongman, K. (2015). Foretelling the history of social work: A Botswana Perspective. IFSW, Berne.

Lub, V. (2019), Theory, social work methods and participation. Journal of Social Work, 19(1), 3-19. https://doi.org/10.1177/1468017318757297

Michael, K., Keller, S., Tran, X., Sayles, H., \& Custer, T. (2016). Student Participation in Professional Organizations: A Synopsis of Data Collected from CAAHEPAccredited Sonography Programs. Journal of Diagnostic Medical Sonography, 32(6), 336-342. https://doi.org/10.1177/8756479316667079

Michie, S., West, R., Campbell, R., Brown, J., \& Gainforth, H. (2014). ABC of behaviour change theories. Sutton, UK: Silverback Publishing.

Ngwenya, B. (1991). Social Work Education and Practice. Social Implications of SAPs in Africa.

Rankopo, M. (1996). Community participation in self-help projects in Botswana. In M. Hutton, \& L-K. Mwansa (Eds.), Social Work Practice in Africa: Social Development in a Community Context. PrintConsult, Gaborone.

Remmer, K. L. (2010). Political Scale and Electoral Turnout: Evidence From the Less Industrialized World. Comparative Political Studies, 43(3), 275-303. https://doi.org/10.1177/0010414009352638

Riuter, J. T. (2011). Bringing the Beneficiary Closer: Explanation for Volunteering Time in Dutch Private Development Initiatives. Non-profit and Voluntary Sector Quarterly.

Steblay, N. M. (1987). Helping Behaviour in Rural and Urban Environments. Ameta Analysis, Phycological Bulletin, 346-356.

Teorell, J. (2003). Linking Social Capital to Political Participation. Voluntary Association and Networks. Scandinavian Political Studies, 26(1), 49-66.

Zaman, W. A. (1984). Public Participation in Development and Health Programs: Lessons from Bangladesh. Lanham: University Press of America, Inc. 


\section{Notes}

Note 1. 2013-2018 AGM REPORTS

Note 2. BONASW NEEDS ASSESSMENT, 2012

\section{Copyrights}

Copyright for this article is retained by the author(s), with first publication rights granted to the journal.

This is an open-access article distributed under the terms and conditions of the Creative Commons Attribution license (http://creativecommons.org/licenses/by/4.0/). 